\title{
BMJ Open Fertility among women living with HIV in western Ethiopia and its implications for prevention of vertical transmission: a cross-sectional
} study

\author{
Tesfaye Regassa Feyissa (D) ,,2 Melissa L. Harris (D) ," ${ }^{1,2}$ eta M. Forder, ${ }^{2}$ \\ Deborah Loxton ${ }^{2}$
}

To cite: Feyissa TR, Harris ML, Forder PM, et al. Fertility among women living with HIV in western Ethiopia and its implications for prevention of vertical transmission: a crosssectional

study. BMJ Open

2020;10:e036391. doi:10.1136/ bmjopen-2019-036391

- Prepublication history for this paper is available online. To view these files, please visit the journal online (http://dx.doi. org/10.1136/bmjopen-2019036391).

Received 12 December 2019

Revised 29 May 2020

Accepted 23 July 2020

Check for updates

(c) Author(s) (or their employer(s)) 2020. Re-use permitted under CC BY-NC. No commercial re-use. See rights and permissions. Published by BMJ.

${ }^{1}$ College of Health Science, Wollega University, Nekemte, Oromia, Ethiopia

${ }^{2}$ Research Centre for Generational Health and Ageing, School of Medicine and Public Health, Faculty of Health and Medicine, University of Newcastle, Newcastle, New South Wales, Australia

Correspondence to Tesfaye Regassa Feyissa; regassatesfaye@gmail.com

\section{ABSTRACT}

Objective This study aimed to examine fertility (live births) in the last 3 years and its associated factors among women living with HIV (WLHIV) in western Ethiopia . Design Participants were recruited into a cross-sectional survey using systematic sampling.

Settings Four healthcare facilities in western Ethiopia were included.

Participants Eligible participants were WLHIV of reproductive age (15-49 years) from western Ethiopia who found out about their HIV-positive status more than 3 years ago $(\mathrm{N}=866)$.

Primary outcome measures The fertility (live births) of HIV-positive women in the last 3 years was surveyed using face-to-face interviews (March-June 2018). Logistic regression analyses were conducted to examine factors influencing fertility in the last 3 years.

Results A total of 108 (12.5\%) HIV-positive women gave birth to 121 live children in the last 3 years. Of these births, $18.2 \%$ were reported as mistimed at conception, while $26.4 \%$ were reported as unwanted. Of the live births, $8.3 \%$ ended in death. Of the $76(62.8 \%)$ children with known HIV status born to HIV-positive women in the last 3 years, $7.9 \%$ were HIV-positive. In terms of predictors of fertility, women aged 15-24 years (adjusted OR (AOR) 2.72; $95 \%$ Cl 1.14 to 6.49) and 25-34 years (AOR 4.34; $95 \% \mathrm{Cl} 2.61$ to 7.21 ) had increased odds of fertility compared with women aged 35-49 years. Women using antiretroviral therapy (ART) for less than 5 years were more likely to have given birth in the last 3 years compared with those using ART for 10 years or more (AOR 2.96; $95 \% \mathrm{Cl}$ 1.19 to 7.36), even after controlling for age.

Conclusions WLHIV in Ethiopia are having children and so it is imperative that safe conception strategies are readily available as well as support to reduce HIV-related risks for children born to these mothers. Strengthening reproductive health services for HIV-positive women in order to achieve their family planning goals is therefore important.

\section{INTRODUCTION}

Fertility refers to the production of live births, ${ }^{1}$ and with a fertility rate of 4.6 births per woman in the general population,
Strengths and limitations of this study

- This is the first study to examine fertility as it relates to live births among women with HIV in Ethiopia.

- Many women with HIV were included in our study and standard mobile-based surveys were used; to minimise bias, the survey was administered by nurses who had never worked in the clinic.

- As our findings depend on a cross-sectional survey, we were unable to model the effect of contraceptive use as an explanatory variable for fertility.

- All data were based on self-reported measures, which may have introduced social desirability and recall bias.

- This study may also be subject to survivor bias since HIV-positive women who were retained in HIV care were more likely to be included in this study.

Ethiopia has one of the highest fertility rates in the world. ${ }^{2}$ The prospect of having children among women living with HIV (WLHIV) raises additional reproductive health concerns. ${ }^{3}$ These include risks associated with vertical transmission of HIV to a child ${ }^{4}$ and horizontal transmission of HIV to a partner, ${ }^{5}$ as well as the risk of acquiring or transmitting drug-resistant strains of HIV. ${ }^{6}$ Importantly, for accurate prevention of mother to child transmission (PMTCT) planning and evaluation, an understanding of fertility among WLHIV is required. However, this is currently lacking in Ethiopia.

In Ethiopia, the first national PMTCT guideline was developed in 2001, with revisions made in 2007, 2011 and 2013 to include global recommendations. ${ }^{7}$ In Ethiopia, the free PMTCT service was launched in 2004 and has been scaled up in the last decade, especially after 2010. ${ }^{7}$ The current PMTCT guideline (2013) is based on the option $\mathrm{B}+$ 
PMTCT protocol $^{8}$ in which all HIV-positive pregnant women are immediately offered antiretroviral therapy (ART) for life regardless of their CD4 count. ${ }^{9}$ While the aim of the PMTCT programme in Ethiopia was to achieve ART coverage of $90 \%$ for HIV-positive pregnant women by $2015,{ }^{10}$ only $55 \%$ of eligible pregnant women received ART for PMTCT in Ethiopia in 2013. ${ }^{11}$ The mother to child transmission (MTCT) rate after breast feeding was also high (18\%). This rate could be reduced to less than $2 \%$ among the non-breastfeeding population (5\% among the breastfeeding population) by a series of interventions. ${ }^{11}$ This rate reduction could be achieved through planning pregnancies, adherence to ART for women and antiretroviral prophylaxis for infants, antenatal care, skilled birth attendance, and engagement in postnatal care such as proper breast feeding. ${ }^{12}$ A retrospective study based on routine data collection in Addis Ababa, Ethiopia showed that the recommendations as a result of the revisions in the PMTCT guideline between 2001 and 2013 led to a $92.3 \%$ reported practice of exclusive breast feeding in 2013 compared with $60.9 \%$ in 2005 . The same study indicated that ART initiation was $62 \%$ in 2013 compared with 0 in 2005. However, it was highlighted that there were serious gaps in the quality of the PMTCT programme implementation. ${ }^{7}$

Despite this, few studies have explored factors associated with having children in WLHIV, particularly in Ethiopia. ${ }^{13}$ A systematic review in sub-Saharan Africa (SSA) examined fertility in relation to four factors: fertility of HIVpositive women relative to HIV-negative women; fertility of HIV-positive women on ART compared with those not yet on ART; time since HIV diagnosis; and time on ART. ${ }^{13}$ Factors affecting fertility in the general population have largely revolved around educational and economic attainment. ${ }^{14}$ A cross-sectional study among women of reproductive age in Ethiopia found that schooling, age, household expenditure and residence predicted fertility independently. ${ }^{15}$ Unlike the general population, fertility among the HIV-positive population may be further influenced by HIV-related factors. ${ }^{13}$ In previous studies, variation in fertility between HIV-positive and HIV-negative women has mainly been described in relation to the age of women. Some studies reported that younger HIVpositive women were more likely to have a child than younger HIV-negative women ${ }^{16}{ }^{17}$; however, evidence for this hypothesis was inconclusive. ${ }^{18}$

Moreover, studies have documented the impact of ART on fertility level, ${ }^{19}{ }^{20}$ following a large-scale ART expansion, with ART restoring physical functioning, ${ }^{21}$ sexual activity ${ }^{22}$ and eventually fertility. ${ }^{23}$ This has been demonstrated by a reduction in the difference in fertility rates over time between HIV-positive women using ART and HIV-negative women, ${ }^{19}$ although there was a lack of suitable comparators. It was also highlighted that a higher rate of conception among women on long-term ART was observed. ${ }^{24}$ However, a recent systematic review documented a lack of strong evidence with regard to the impact of ART on the fertility of WLHIV. ${ }^{13}$ Furthermore, a study from two Nordic countries showed that CD $4>350$ cells $/ \mathrm{mm}^{3}$ was associated with increased fertility ${ }^{25}$ and that people who started ART when their CD4 count was $<350$ cells $/ \mathrm{mm}^{3}$ rarely achieved $\mathrm{CD} 4>500$ cells $/ \mathrm{mm}^{3}$ after 10 years. ${ }^{26} 27$ Given these studies might have limited applicability among WLHIV in Ethiopia, there is a great need for studies that examine fertility among WLHIV.

Examining rates and predictors of fertility among WLHIV as ART scales up is essential to planning and supporting the prevention of HIV, in addition to supporting other reproductive health services. To the best of our knowledge, this is the first study to evaluate fertility among WLHIV in Ethiopia. This study examined the following two research questions: What are the factors associated with fertility (live births) in the last 3 years among WLHIV in western Ethiopia? What are the demographic characteristics of children born in the last 3 years to HIV-positive women in western Ethiopia? In this study, we therefore sought to (1) describe fertility (live births) in the last 3 years among WLHIV in western Ethiopia; and (2) assess factors associated with fertility (live births) in the last 3 years among WLHIV in western Ethiopia.

\section{METHODS AND MATERIALS}

\section{Study design and setting}

A facility-based, cross-sectional survey was conducted among WLHIV in two zones (East and West Wollega Zones) of western Ethiopia between March and June 2018. The survey has three objectives: (1) to examine fertility among WLHIV in western Ethiopia in the last 3 years; (2) to assess contraceptive use among sexually active WLHIV in western Ethiopia; and (3) to assess discussions between healthcare providers and sexually active WLHIV with regard to their reproductive plans in western Ethiopia.

In 2016, the estimated total population of the East and West Wollega Zones was 1558097 and 1724 070, respectively. ${ }^{28}$ Nekemte and Gimbi are the capitals of the respective zones, which are located $328 \mathrm{~km}$ and $440 \mathrm{~km}$ west of the capital city, Addis Ababa. Two healthcare facilities from Nekemte (Nekemte Specialized Hospital and Nekemte Health Center) and two from Gimbi (Gimbi Adventist Hospital and Gimbi Health Center) were included in this study. All selected healthcare facilities were public, except for Gimbi Adventist Hospital, which was supported by a faith-based organisation. However, all HIV clinics were supported by the Ministry of Health of Ethiopia, served all HIV-positive people who need their services and provided ART for free. The Strengthening the Reporting of Observational Studies in Epidemiology for cross-sectional reporting guideline was used ${ }^{29}$ (see online supplementary 1 ).

\section{Study population and sampling}

The recent treat-all policy in Ethiopia meant there were no criteria barriers (eg, CD4 and AIDS stage) to starting $\mathrm{ART}^{30}$ all people living with HIV can commence ART immediately after a HIV-positive diagnosis. To facilitate 
this in Ethiopia, a unique ART number is assigned to people living with HIV to monitor their ART treatment and HIV management, and to coordinate care across different settings. For the recruitment process, a list of ART clients (each with a unique ART number) was thus obtained from the daily appointment calendar, excluding the personal identifiers of each client. A systematic sampling process was used to select study participants. Systematic sampling is the sampling method that requires selecting samples based on a system of intervals $\left(\mathrm{K}^{\text {th }}\right.$ interval) from the sampling frame. ${ }^{31}$ It is similar to simple random sampling, but is easier to apply in practice. ${ }^{31}$

All women of reproductive age (15-49 years) living with HIV were eligible for the survey. Women who were critically ill were excluded for ethical reasons. Among the 2445 HIV-positive women of reproductive age (aged 15-49 years) attending the four healthcare facilities, a prearrival systematic sampling of every second woman was used to select potential study participants, with selected WLHIV invited to participate in the study. All participants were contacted at an HIV clinic at one of the four selected health institutions when they came for their ART services.

Eligibility for this analysis was restricted to WLHIV aged between 15 and 49 years who had known their HIVpositive status for more than 3 years. Of the 1082 WLHIV who were surveyed, a total of 866 WLHIV who learnt their HIV positive status more than 3 years ago met the eligibility criteria and were included for analysis.

\section{Data collection procedures}

The survey questionnaire was prepared in English and was derived from the Ethiopian Demographic and Health Survey and other literature. ${ }^{32}{ }^{33}$ It was then translated into the local language, Oromo. Five female trained data collectors administered a face-to-face, mobile-based survey after 5 days of training and pilot testing. A faceto-face survey was conducted since only $42 \%$ of women were literate and only $0.7 \%$ of women in rural areas had completed secondary school. ${ }^{34}$ The data collectors were female nurses with at least a diploma and were recruited based on their previous experience in data collection, previous training in HIV counselling and local language fluency. Moreover, the data collectors were never involved in the participants' care. Data quality was assured at all stages of research. Data collection was conducted using four iPads and one Samsung S2. The offline REDCap software $^{35}$ was used for data collection.

All participants provided verbal informed consent prior to survey administration.

\section{Measurements \\ Primary outcome \\ Fertility in the last 3 years was measured by a woman having a live birth in the last 3 years prior to data collec- tion (yes/no).}

Secondary outcomes

Descriptions of fertility (in the last 3 years) included the following: total number of children, sex of the child, status of children born in the last 3 years (alive/dead) and HIV status of the child (HIV-positive/HIV-negative/ unknown). Pregnancy intention was also surveyed by whether each birth in the last 3 years was intended (wanted then), mistimed (wanted later) or unwanted (not at all). Finally, whether the child was breast fed (yes/ no); exclusively breast fed (EBF) (EBF for 6 months; not EBF if started on additional food before 6 months); and duration of breast feeding (months) for children aged 6 months or more were also measured. For mothers who had more than one child in the 3 years before the survey, breast feeding was measured for the last-born child.

\section{Explanatory variables}

The selection of variables for analysis was based on prior research and evidence. ${ }^{131525}$ Where practical and available, variables that were reported from the existing literature to influence fertility were selected for the analytic component.

- Sociodemographic characteristics: healthcare facility, age, residence, schooling, family size, marital status, number of previous children, monthly family income, main decision-maker regarding income use and primary occupation. Mobile phone use, watching television and listening to radio were also assessed $^{34}$ (table 1).

- HIV-related factors: time since HIV diagnosis, time on ART, reported health status since ART commenced and most recent CD4 count. ${ }^{30} 36$ Given CD4 count was measured regularly (every 3-6 months), the most recent CD4 measure was asked for. ${ }^{30}$ Current partner test status for HIV and the HIV status of tested partner were also assessed (table 2).

- Reproductive health history: ever pregnant, age at first pregnancy, ever given birth, age at first birth, children living in the household (yes/no), number of children living in the household, children not living with their mother at home (yes/no), number of children not living with their mother at home, children deceased, total number of children deceased, total number of children deceased since HIV diagnosis, number of children born since HIV diagnosis, ever had a termination/stillbirth, termination/stillbirth in the last 3 years and gestational age at termination (table 3 ).

\section{Statistical analyses}

Descriptive statistics (frequencies and percentages) were used to summarise the data. For the primary outcome variable, logistic regressions were conducted for fertility in the last 3 years (binary outcome: yes/no). Univariable logistic regression models were used to obtain the unadjusted associations between fertility in the last 3 years and each of the independent variables. All variables that were tested for association with fertility in the last 3 years 
Table 1 Characteristics of the cohort of women living with HIV in western Ethiopia, 2018 (N=866)

\begin{tabular}{|c|c|c|c|}
\hline Characteristics & Categories & $\mathbf{n}$ & $\%$ \\
\hline \multirow[t]{2}{*}{ Healthcare facility } & Hospital & 620 & 71.6 \\
\hline & Health centre & 246 & 28.4 \\
\hline & $25-34$ & 322 & 37.2 \\
\hline & $35-49$ & 485 & 56.0 \\
\hline \multirow[t]{2}{*}{ Residence } & Urban & 800 & 92.4 \\
\hline & Rural & 66 & 7.6 \\
\hline \multirow[t]{3}{*}{ Educational status } & No formal education & 190 & 22.0 \\
\hline & Primary education & 436 & 50.5 \\
\hline & Secondary education & 175 & 20.3 \\
\hline \multirow[t]{4}{*}{ Family size } & $1-2$ & 217 & 25.1 \\
\hline & $3-4$ & 421 & 48.8 \\
\hline & 5 or more & 225 & 26.1 \\
\hline & Missing & 3 & \\
\hline Family size* & & $3.6(1.6)$ & \\
\hline \multirow[t]{3}{*}{ Number of previous children (more than 3 years) } & 2 or fewer & 531 & 61.6 \\
\hline & 3 or more & 331 & 38.4 \\
\hline & Missing & 4 & \\
\hline Marital status & Married & 429 & 49.9 \\
\hline \multirow[t]{5}{*}{ Main decision-maker regarding income use } & Respondent & 545 & 64.3 \\
\hline & Husband/partner & 114 & 13.4 \\
\hline & Respondent and husband/partner jointly & 165 & 19.5 \\
\hline & Others $†$ & 24 & 2.8 \\
\hline & Missing & 16 & \\
\hline \multirow[t]{7}{*}{ Primary occupation } & Farmer & 35 & 4.0 \\
\hline & Labourer & 354 & 40.9 \\
\hline & Governmental employee & 99 & 11.4 \\
\hline & Non-governmental employee & 42 & 4.9 \\
\hline & Small business owner/trader & 172 & 19.9 \\
\hline & Housewife & 143 & 16.5 \\
\hline & Other, specify $\ddagger$ & 21 & 2.4 \\
\hline \multirow[t]{4}{*}{ Mobile phone use } & Almost every day & 578 & 66.7 \\
\hline & At least once a week & 80 & 9.2 \\
\hline & Less than once a week & 6 & 0.7 \\
\hline & Not at all & 202 & 23.3 \\
\hline
\end{tabular}




\begin{tabular}{|c|c|c|c|}
\hline Characteristics & Categories & $\mathbf{n}$ & $\%$ \\
\hline \multirow[t]{4}{*}{ Watch television } & Almost every day & 490 & 56.6 \\
\hline & At least once a week & 46 & 5.3 \\
\hline & Less than once a week & 7 & 0.8 \\
\hline & Not at all & 323 & 37.3 \\
\hline \multirow[t]{5}{*}{ Listen to radio } & Almost every day & 176 & 20.4 \\
\hline & At least once a week & 59 & 6.8 \\
\hline & Less than once a week & 19 & 2.2 \\
\hline & Not at all & 610 & 70.6 \\
\hline & Missing & 2 & \\
\hline
\end{tabular}

${ }^{*}$ Continuous variable, mean and SD presented.

†Father, mother, relative, family and siblings.

$\ddagger$ Student, housemaid, retired, volunteer services and support.

in the univariate models were considered in the multivariable logistic regression model to control for possible confounding factors. The final multivariable model included all variables with a p value of $<0.05$ at the univariable level. The strength of association was expressed as adjusted OR (AOR) with 95\% CI. No evidence of collinearity was observed between variables (results not shown). All data processing and analyses were conducted using STATA ${ }^{\circledR}$, version 14 (Stata Corporation, College Station, TX, USA).

\section{Patient and public involvement}

No patient was involved in the development of the research questions and outcome measures, study design or recruitment, and in the conduct of this study.

\section{RESULTS}

\section{Sociodemographic characteristics of WLHIV}

A total of 866 WLHIV who learnt of their HIV-positive status for more than 3 years prior to data collection were included in this study (table 1 ). The mean age was 34.3 years, with $59(6.8 \%)$ participants aged between 15 and 24 years and $485(56 \%)$ participants aged 35 or older. Many of the women $(71.6 \%)$ were recruited through hospitals, and nearly all participants $(92.4 \%)$ resided in urban areas. The mean household family size was 3.6 people, with $55.4 \%$ of participants reporting a monthly household income of less than 1500 Ethiopian Birr (US\$53.76).

\section{HIV-related characteristics of participants}

Of the 866 women, nearly $85 \%$ had known of their HIVpositive status for at least 5 years, with an average time of HIV-positive awareness of 8.7 years across all women (table 2). About 25.4\% of WLHIV aged 15-24 years and $44.8 \%$ of WLHIV aged 35-49 years had known of their HIV-positive status for at least 10 years. All women were using ART (results not shown), and 29.4\% (20.3\% of WLHIV aged 15-24 years and 35\% of WLHIV aged 35-49 years) had been receiving ART for 10 years or longer.
Only 20\% of WLHIV had recent CD4 counts of less than 350 cells $/ \mathrm{mm}^{3}$, with an overall mean $\mathrm{CD} 4$ count of 611.7 cells $/ \mathrm{mm}^{3}$. Three hundred and seventy $(81.7 \%)$ participants were aware that their partners had been tested for HIV, and of those partners who were tested around a third were reported to be HIV-negative.

\section{Reproductive history of WLHIV in western Ethiopia}

A total of $750(87 \%)$ participants reported ever being pregnant (table 3). More than half of these participants reported that their first pregnancy occurred during their teenage years $(2.9 \%$ when they were 14 years or younger and $50.5 \%$ between 15 and 19 years). Among women who had ever been pregnant, 734 (97.9\%) gave birth; $2.7 \%$ gave birth when they were 14 years or younger, while $49.2 \%$ had their first birth between 15 and 19 years. Among women who had ever given birth, 650 (88.7\%) had children living in the household, of whom $66.3 \%$ had one to two children living in the household. One hundred and fifty-four $(21.1 \%)$ women reported death of a child, of whom $89.6 \%$ reported one to two deaths.

Furthermore, $25.7 \%$ gave birth to one child since HIV diagnosis. Among women who were ever pregnant, 109 (14.5\%) reported a history of abortion/stillbirth. Among these, $15.9 \%$ experienced them in the last 3 years. About three-quarters $(52.9 \%)$ terminated a pregnancy before 20 weeks.

Fertility characteristics among women who had given birth in the last 3 years

Among the 866 women, 108 (12.5\%; 16.9\% among WLHIV aged 15-24 years and 5.2\% among WLHIV aged 35-49 years) had given birth in the last 3 years to 121 children. Among these children, 49.6\% were male and $8.3 \%$ died. Among children with known HIV status (62.8\%), $7.9 \%$ were reported to be HIV-positive. Just over half of recent births $(55.4 \%$; $60.0 \%$ among WLHIV aged 15-24 years and 55.2\% among WLHIV aged 35-49 years) were intended, with a further $18.2 \%$ being reported as 
Table 2 HIV-related characteristics among the cohort of women living with HIV in western Ethiopia, 2018 ( $N=866$ )

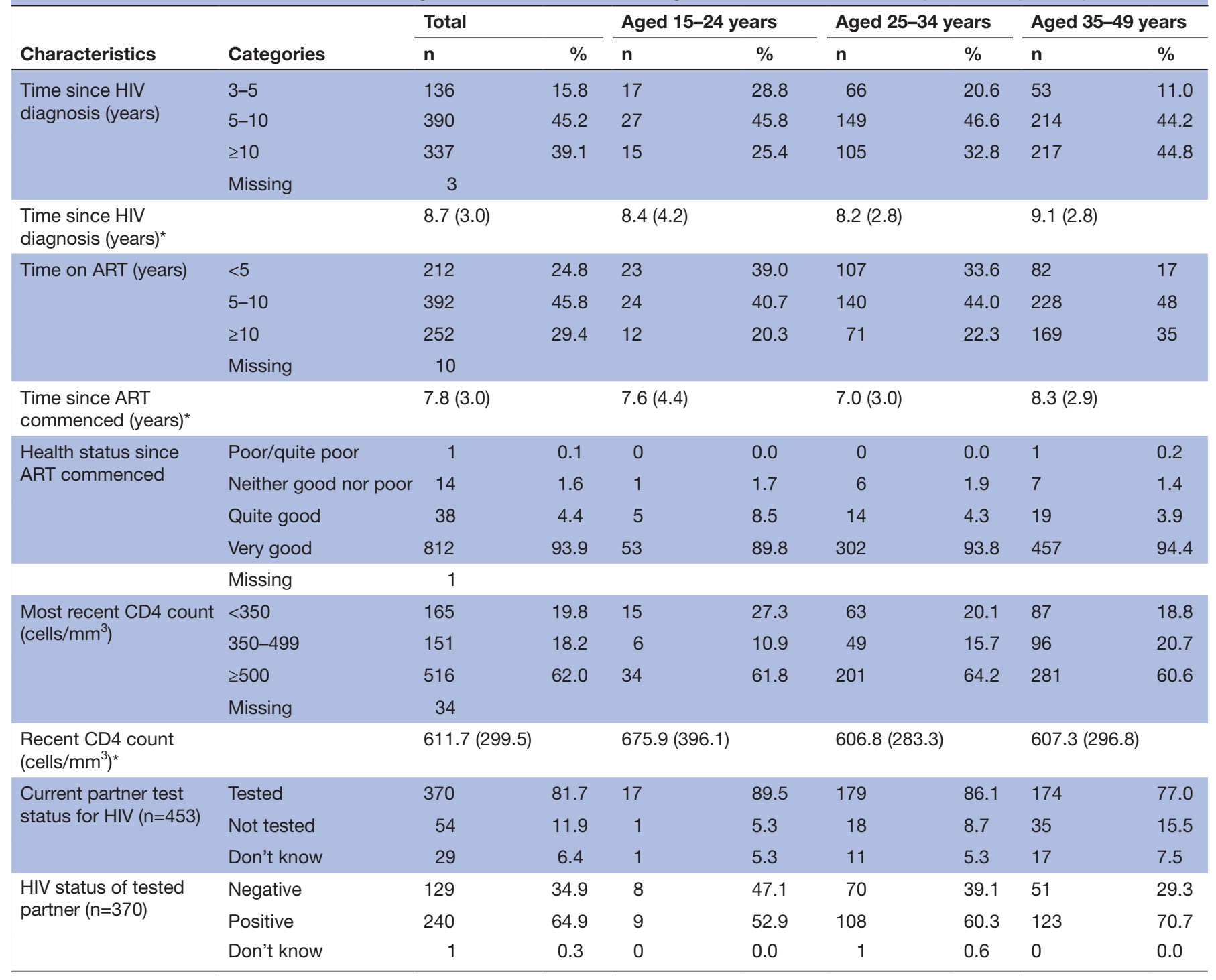

${ }^{*}$ Continuous variable, mean and SD presented.

ART, antiretroviral therapy.

mistimed at conception and $26.4 \%$ being reported as unwanted births. Ninety-nine $(92.5 \%)$ children were breast fed. Among children aged greater than 6 months, $81.1 \%$ were EBF, with a mean breastfeeding period of 6.3 months (see table 4).

\section{Predictors of fertility among WLHIV in western Ethiopia}

At a univariable level, age, healthcare facility, residence, income, number of previous children, time since HIV diagnosis and time on ART were associated with fertility in the last 5 years. From the final multivariable model, women aged 15-24 years and women aged 25-34 years were more likely to report fertility in the last 3 years compared with women aged 35-49 years (AOR 2.72; 95\% CI 1.14 to 6.49 and AOR 4.34; $95 \%$ CI 2.61 to 7.21 , respectively). Compared with women who reported having two or fewer previous children, having three or more previous children (AOR $=0.57 ; 95 \%$ CI 0.34 to 0.95 ) was associated with decreased odds of fertility in the last 3 years. Women who were using ART for less than 5 years (AOR 2.96; 95\% CI 1.19 to 7.36) were more likely to have given (live) birth in the last 3 years compared with women who were using ART for 10 years or more (see table 5).

\section{DISCUSSION}

This study aimed to examine fertility experienced in the last 3 years among WLHIV in western Ethiopia. We found that women with HIV are having live births. Women aged 15-24 years and 25-34 years had increased odds of fertility compared with women aged $35-49$ years. Women using ART for less than 5 years were more likely to have given live birth in the last 3 years compared with those using ART for 10 years or more. This highlights the need for providing services that ensure safe conception and 
Table 3 Reproductive history among the cohort of women living with HIV in western Ethiopia, 2018

\section{Characteristics* $^{*}$}

Categories

n

$\%$

All women $(\mathrm{N}=866)$

Ever pregnant

Yes

750

87.0

No

112

13.0

Missing

4

Women who reported ever being pregnant $(n=750)$

\begin{tabular}{|c|c|c|c|}
\hline \multirow[t]{6}{*}{ Age at first pregnancy } & $\leq 14$ & 22 & 2.9 \\
\hline & $15-19$ & 379 & 50.5 \\
\hline & $20-24$ & 255 & 34.0 \\
\hline & $25-29$ & 70 & 9.3 \\
\hline & 30-35 & 12 & 1.6 \\
\hline & Don't know & 12 & 1.6 \\
\hline \multirow[t]{2}{*}{ Ever gave birth } & Yes & 734 & 97.9 \\
\hline & No & 16 & 2.1 \\
\hline \multirow[t]{2}{*}{ Ever had abortion/stillbirth } & Yes & 109 & 14.5 \\
\hline & No & 641 & 85.5 \\
\hline \multicolumn{4}{|l|}{ Women who reported ever giving birth $(n=734)$} \\
\hline \multirow[t]{6}{*}{ Age at first birth } & $\leq 14$ & 20 & 2.7 \\
\hline & $15-19$ & 361 & 49.2 \\
\hline & $20-24$ & 256 & 34.9 \\
\hline & $25-29$ & 75 & 10.2 \\
\hline & $30-36$ & 9 & 1.2 \\
\hline & Don't know & 2 & 0.3 \\
\hline \multirow[t]{3}{*}{ Deceased children } & Yes & 154 & 21.1 \\
\hline & No & 576 & 78.9 \\
\hline & Missing & 4 & \\
\hline \multirow[t]{6}{*}{ Number of children born since HIV diagnosis } & No & 453 & 61.8 \\
\hline & 1 & 188 & 25.7 \\
\hline & 2 & 78 & 10.6 \\
\hline & 3 & 14 & 1.9 \\
\hline & Total children & 386 & \\
\hline & Missing & 1 & \\
\hline \multirow[t]{3}{*}{ Children living in the household } & Yes & 650 & 88.7 \\
\hline & No & 83 & 11.3 \\
\hline & Missing & 1 & \\
\hline \multirow[t]{3}{*}{ Children not living with their mother at home } & Yes & 257 & 35.6 \\
\hline & No & 465 & 64.4 \\
\hline & Missing & 12 & \\
\hline \multicolumn{4}{|l|}{ More on reproductive history } \\
\hline \multirow[t]{3}{*}{ Number of children living in the household $(n=650)$} & $1-2$ & 431 & 66.3 \\
\hline & $3-4$ & 189 & 29.1 \\
\hline & 5 or more & 30 & 4.6 \\
\hline \multirow[t]{3}{*}{ Number of children not living with their mother at home $(n=232)$} & $1-2$ & 183 & 78.9 \\
\hline & $3-4$ & 43 & 18.5 \\
\hline & 5 or more & 6 & 2.6 \\
\hline
\end{tabular}

Continued 


\begin{tabular}{|c|c|c|c|}
\hline Characteristics* & Categories & $\mathbf{n}$ & $\%$ \\
\hline Total number of children deceased $(n=154)$ & $1-2$ & 138 & 89.6 \\
\hline \multirow[t]{2}{*}{ Total number of children deceased since HIV diagnosis $(n=152)$} & No & 114 & 75.0 \\
\hline & 1 & 34 & 22.4 \\
\hline \multirow[t]{2}{*}{ Abortion/stillbirth in the last 3 years $(n=109)$} & Yes & 17 & 15.6 \\
\hline & No & 92 & 84.4 \\
\hline \multirow[t]{2}{*}{ Gestational age at termination $(n=17)$ (months) } & $<5$ & 9 & 52.9 \\
\hline & $5-7$ & 2 & 11.8 \\
\hline
\end{tabular}

*Sample indicated for each variable separately.

pregnancy for WLHIV, particularly for women in their prime childbearing years $(<35$ years $)$ and those with recent uptake of ART ( $<5$ years).

The fertility rate among WLHIV in our study is slightly lower than the general fertility rate of the general female population of Ethiopia for the 3 years preceding the survey (160 live births per 1000 women aged 15-49 years). ${ }^{32}$ This lower fertility rate among HIV-positive women compared with HIV-negative women might be related to reduced fecundity (the ability to have live births) among HIV-positive people. ${ }^{37}$ For HIV-positive populations, fertility raises concerns over vertical transmission of HIV (a significant number of children born to these women became HIV-positive), highlighting that a lack of effective interventions for the PMTCT programmes continues to undermine efforts to eliminate new HIV infections among children. A retrospective study from Addis Ababa, Ethiopia showed that $4 \%$ of HIV-exposed children were HIV-positive by 18 months. ${ }^{7}$ In 2013, about half of eligible pregnant women $(55 \%)$ received ART for PMTCT, and MTCT after breast feeding was high (18\%) in Ethiopia. ${ }^{11}$ MTCT could be reduced to less than $2 \%$ in non-breastfeeding populations or $<5 \%$ in breastfeeding populations. ${ }^{11}$ This rate reduction could be achieved through proper support, such as preconception planning, adherence to ART for women and antiretroviral prophylaxis for infants, and skilled maternal health service utilisation, as well as appropriate infant feeding. ${ }^{12}$ In our study, $8.3 \%$ of children died, and these deaths could have been related to HIV infection. It is therefore important to strengthen interventions for WLHIV to reduce child mortality by improving pregnancy planning and averting unplanned births when HIV status has not been considered. ${ }^{38}$ Given the lack of policies and guidelines regarding safer conception strategies in relation to CD4 level, treatment regimen and viral load, ${ }^{39}$ as well as lack of guidelines regarding contraception specific to WLHIV in Ethiopia, ${ }^{7}$ addressing these critical intervention areas is essential to reducing some of the risks of
HIV transmission to children and child mortality in this population.

Furthermore, family planning is a key strategy to prevent HIV transmission from the mother to the child. ${ }^{40}$ WLHIV can use many of the available contraceptive methods without any restriction. Contraceptive methods that are available in Ethiopia include implants, intrauterine devices, injectables, pills, condoms, sterilisation and emergency contraception. ${ }^{2}$ A 2013 cross-sectional study in the Tigray Region of Ethiopia showed that $44.3 \%$ of WLHIV were using some form of contraception. Injectables $(70.7 \%)$ and male condoms $(47.6 \%)$ were the most commonly used type of contraceptives. ${ }^{41}$ Improving the availability and utilisation of effective contraception might serve as a crucial step in pursuing reproductive goals as well as supporting the PMTCT programmes by preventing unintended pregnancies. ${ }^{40}$

Education and interventions regarding safer conception in the context of HIV could support the prevention of new HIV infections. ${ }^{42}$ Frequent visits by WLHIV to HIV clinics for ART services after HIV diagnosis ${ }^{43}$ create an opportunity to use counselling and support regarding both conception and contraception. Fertility planning is also important for this population mainly due to high serodiscordance as well as the unknown HIV status of the partner in our study.

Furthermore, fertility should be an issue for clinicians and policymakers, considering that there was a high rate of unintended births as well as a significant number of WLHIV who reported having an abortion in our study. With the assumption that these unintended births are related to either an unmet need for contraception or contraceptive failure, ${ }^{44}$ improving family planning programmes could play a critical role in the PMTCT programmes through prevention of unintended births which could be HIV-positive.

To prevent vertical HIV transmission, comprehensive PMTCT programmes such as infant feeding programmes need proper implementation and evaluation. ${ }^{7}$ Given 
Table 4 Fertility characteristics in the last 3 years among the cohort of women living with HIV in western Ethiopia, 2018

\begin{tabular}{|c|c|c|c|c|c|c|c|c|c|}
\hline \multirow[b]{2}{*}{ Characteristics } & \multirow[b]{2}{*}{ Categories } & \multirow[b]{2}{*}{$\mathbf{n}$} & \multirow[b]{2}{*}{$\%$} & \multicolumn{2}{|c|}{ Aged 15-24 years } & \multicolumn{2}{|c|}{ Aged 25-34 years } & \multicolumn{2}{|c|}{ Aged $35-49$ years } \\
\hline & & & & $\mathbf{n}$ & $\%$ & $\mathbf{n}$ & $\%$ & $\mathbf{n}$ & $\%$ \\
\hline \multicolumn{10}{|l|}{ All women $(\mathrm{N}=866)$} \\
\hline \multirow{2}{*}{$\begin{array}{l}\text { Births in the last } 3 \\
\text { years }\end{array}$} & No & 753 & 87.5 & 49 & 83.1 & 248 & 77.3 & 456 & 94.8 \\
\hline & $\begin{array}{l}\text { Total of live } \\
\text { births }\end{array}$ & 121 & & & & & & & \\
\hline
\end{tabular}

Characteristics of all births in the last 3 years $(\mathrm{n}=121)$

\begin{tabular}{|c|c|c|c|c|c|c|c|c|c|}
\hline \multirow[t]{2}{*}{ Sex of child } & Male & 60 & 49.6 & 6 & 60.0 & 41 & 50.0 & 13 & 44.8 \\
\hline & Female & 61 & 50.4 & 4 & 40.0 & 41 & 50.0 & 16 & 55.2 \\
\hline \multirow{2}{*}{$\begin{array}{l}\text { Status of children born } \\
\text { in the last } 3 \text { years }\end{array}$} & Alive & 105 & 86.8 & 9 & 90.0 & 71 & 92.2 & 27 & 96.4 \\
\hline & Missing & 6 & & & & & & & \\
\hline \multirow[t]{2}{*}{ Pregnancy intention } & Intended & 67 & 55.4 & 6 & 60.0 & 45 & 54.9 & 16 & 55.2 \\
\hline & Unwanted & 32 & 26.4 & 1 & 10.0 & 22 & 26.8 & 9 & 31.0 \\
\hline \multirow{2}{*}{$\begin{array}{l}\text { Knowledge of child's } \\
\text { HIV status }\end{array}$} & Known & 76 & 62.8 & 10 & 62.5 & 82 & 72.6 & 29 & 72.5 \\
\hline & Unknown & 45 & 37.2 & 6 & 37.5 & 31 & 27.4 & 11 & 27.5 \\
\hline \multirow{2}{*}{$\begin{array}{l}\text { Child's HIV status } \\
(\mathrm{n}=76)\end{array}$} & HIV-negative & 70 & 92.1 & 3 & 75.0 & 47 & 92.2 & 20 & 95.2 \\
\hline & HIV-positive & 6 & 7.9 & 1 & 25.0 & 4 & 7.8 & 1 & 4.8 \\
\hline \multirow{2}{*}{ Breast fed index child } & No & 8 & 7.5 & 1 & 10.0 & 5 & 6.9 & 2 & 8.0 \\
\hline & Missing & 1 & & & & & & & \\
\hline \multirow{3}{*}{$\begin{array}{l}\text { Exclusive breast } \\
\text { feeding of children } \\
\text { aged greater than } 6 \\
\text { months }(n=95)\end{array}$} & Yes & 77 & 81.1 & 6 & 66.7 & 53 & 82.8 & 18 & 81.8 \\
\hline & No & 18 & 19.0 & 3 & 33.3 & 11 & 17.2 & 4 & 18.2 \\
\hline & Missing & 1 & & & & & & & \\
\hline $\begin{array}{l}\text { Mean exclusive breast } \\
\text { feeding of index child } \\
\text { ( } n=87) \text { (months) }\end{array}$ & & 6.3 & & 5.7 & & 6.4 & & 6.3 & \\
\hline
\end{tabular}

a third to a half of HIV transmission to children could likely have occurred through breast feeding, ${ }^{45}$ supporting breast feeding needs special attention. In our study, most women breast fed their children and four-fifths of these women exclusively breast fed. During breast feeding, there is a risk of HIV transmission to the child, which is increased with longer duration of breast feeding as well as poor breastfeeding practices. ${ }^{11}$ Regrettably, an estimated 110000 children acquired HIV during birth or breast feeding in 2017 in SSA alone, ${ }^{46}$ contributing to more than $90 \%$ of HIV infections in children. ${ }^{47}$ Therefore, breast feeding among WLHIV might require further support, given the rate of HIV infection in children in our study.

In our study, younger aged women (15-24 years) and women aged 25-34 years were about three and four times more likely to have live births in the last 3 years compared with women aged 35-49 years, respectively. This shows the fertility of women with HIV does not differ by age compared to the general population of Ethiopia. ${ }^{32}$ This finding is also consistent with studies from Uganda, ${ }^{4} 49$ which is likely to be related to younger women being more fertile. ${ }^{50}$ In Ethiopia, majority of women give birth for the first time during their teenage years $(53.1 \%),{ }^{34}$ which was also observed among WLHIV in our study. Addressing the risks of too early childbearing could have a significant benefit in improving the health of mothers and children. Another possible explanation for higher fertility among younger women is related to their lack of access to effective contraception. ${ }^{51}$ Consequently, this highlights the importance of support for all WLHIV, including younger 
Table 5 Factors associated with fertility in the last 3 years among the cohort of women living with HIV in western Ethiopia, 2018

\begin{tabular}{|c|c|c|c|c|c|}
\hline \multirow[b]{2}{*}{ Characteristics } & \multirow[b]{2}{*}{ Categories } & \multicolumn{2}{|c|}{$\begin{array}{l}\text { Fertility in the last } \\
3 \text { years }\end{array}$} & \multirow[b]{2}{*}{ Unadjusted OR (95\% Cl) } & \multirow[b]{2}{*}{ Adjusted OR $(95 \% \mathrm{Cl}$} \\
\hline & & Yes & No & & \\
\hline \multirow[t]{3}{*}{ Age (years) } & $15-24$ & 10 & 49 & 3.72 (1.69 to 8.20$)$ & 2.72 (1.14 to 6.49$)$ \\
\hline & $25-34$ & 73 & 248 & 5.37 (3.32 to 8.67 ) & 4.34 (2.61 to 7.21$)$ \\
\hline & $35-49$ & 25 & 456 & Ref & Ref \\
\hline \multirow[t]{2}{*}{ Residence } & Urban & 107 & 689 & Ref & Ref \\
\hline & Rural & 1 & 64 & $0.10(0.01$ to 0.73$)$ & 0.13 (0.02 to 1.00$)$ \\
\hline \multirow[t]{3}{*}{ Monthly family income } & $<1500$ Birr & 59 & 420 & 7.30 (0.99 to 53.83 ) & 5.39 (0.70 to 41.35$)$ \\
\hline & $\geq 1500$ Birr & 48 & 281 & 8.88 (1.20 to 65.78$)$ & 6.72 (0.87 to 51.82$)$ \\
\hline & Don’t know & 1 & 52 & Ref & Ref \\
\hline \multirow{2}{*}{$\begin{array}{l}\text { Number of previous } \\
\text { children (more than } 3 \text { years) }\end{array}$} & 2 or fewer & 83 & 448 & Ref & Ref \\
\hline & 3 or more & 25 & 305 & $0.44(0.28$ to 0.71$)$ & 0.57 (0.34 to 0.95$)$ \\
\hline \multirow{3}{*}{$\begin{array}{l}\text { Time since HIV diagnosis } \\
\text { (years) }\end{array}$} & $3-5$ & 24 & 110 & 1.87 (1.06 to 3.29$)$ & 0.51 (0.20 to 1.27$)$ \\
\hline & $5-10$ & 49 & 340 & 1.24 (0.78 to 1.96$)$ & 0.67 (0.33 to 1.37$)$ \\
\hline & $\geq 10$ & 35 & 300 & Ref & Ref \\
\hline \multirow[t]{3}{*}{ Time on ART (years) } & $<5$ & 41 & 169 & 2.65 (1.51 to 4.64$)$ & 2.96 (1.19 to 7.36$)$ \\
\hline & $5-10$ & 44 & 347 & 1.38 (0.80 to 2.39$)$ & $1.50(0.66-3.40)$ \\
\hline & $\geq 10$ & 21 & 229 & Ref & Ref \\
\hline \multirow{3}{*}{$\begin{array}{l}\text { Recent CD4 count (cells/ } \\
\mathrm{mm}^{3} \text { ) }\end{array}$} & $<350$ & 14 & 151 & Ref & Ref \\
\hline & $350-499$ & 17 & 134 & 1.37 (0.65 to 2.88$)$ & 1.65 (0.75 to 3.60$)$ \\
\hline & $\geq 500$ & 74 & 440 & 1.81 (1.00 to 3.31$)$ & 1.71 (0.91 to 3.22$)$ \\
\hline
\end{tabular}

Values in bold are those significantly associated with outcome variable at $95 \% \mathrm{CL}$.

ART, antiretroviral therapy; Ref, reference.

people because they face the challenges of higher risks of both HIV and fertility. ${ }^{34} 484952$

Having three or more previous children was associated with decreased odds of fertility in the last 3 years compared with women who reported having two or fewer previous children. Promoting effective contraception for those who do not want to have children ${ }^{53}$ and supporting safer conception strategies among those who wanted to have children ${ }^{54}$ could support the prevention of vertical transmission of HIV to a child. ${ }^{4}$ Healthcare provider initiation of reproductive plan discussions with WLHIV in resource-limited countries like Ethiopia ${ }^{55}$ can support achieving their fertility goals.

Given that HIV transmission in Ethiopia mainly occurs through heterosexual transmission, ${ }^{56}$ addressing concerns of WLHIV when they try to conceive is of paramount importance, considering a third of WLHIV were in a serodiscordant relationship in our study. Having children in a serodiscordant relationship might partially explain the persistent rate of new adult HIV infections. ${ }^{57} 58$ In particular, the risk of HIV transmission to uninfected partners doubles when conception occurs compared with when no conception occurs among serodiscordant couples. ${ }^{43}$
Reducing the risks should therefore be one of the critical interventions if women intend to have a child, as assisted reproductive services such as artificial insemination and sperm washing are geographically and economically inaccessible in the study setting. ${ }^{39} 59$ The finding stresses that policies and services supporting fertility planning should be in place so that this population achieves their family planning choice with minimal risks.

Unlike previous studies which showed that a longer period of ART use could result in higher fertility, ${ }^{19} 2023$ our study showed women who were using ART for less than 5 years were more likely to have live births compared with those who were using ART for 10 years or more. However, a recent systematic review revealed that the available evidence is insufficient to describe how ART affects the fertility of WLHIV. ${ }^{13}$ For example, a study from Kenya and Uganda showed no difference in fertility due to ART use. ${ }^{60}$ Importantly, a study from South Africa showed fertility increased with ART when women had better CD4 counts and better ART adherence. ${ }^{61}$ We have to be cautious about the association between time on ART and fertility because women who were better engaged in HIV care and treatment might be different with respect to 
childbearing than women who had dropped out of care (thus were not eligible to be sampled). Further research using longitudinal studies is thus very important. Further research is also required to evaluate the impact of ART utilisation on fertility, particularly with a recent change in the 2015 WHO guideline to avoid delay in ART initiation. ${ }^{30}$ Further investigation in relation to viral load may be required, as a Ugandan study showed higher viral load was associated with reduced fertility. ${ }^{62}$

Although our study provides good insight into the fertility in the last 3 years among WLHIV, it is not without limitations. First, as our findings were based on a crosssectional survey, we are unable to model the effect of contraceptive use as an explanatory variable for fertility. Second, there may be survivor bias because HIV-positive women who were retained in HIV care were more likely to be included in this study. Third, fertility may have been under-reported due to the taboos associated with reporting early neonatal death in Ethiopia. ${ }^{63}$ Fourth, all data were based on self-reported measures, which may have introduced social desirability and recall bias. Nevertheless, to minimise bias, the survey was administered by nurses who had never worked in the clinic. Moreover, many women with HIV were included in our study and standard mobile-based surveys were used.

\section{CONCLUSION}

In conclusion, our findings in western Ethiopia suggest policymakers and programme implementers should offer safe conception options for WLHIV, given many WLHIV are having children. In particular, while supporting these women is required to reduce HIV-related health risks for those choosing conception, effective contraception methods are crucial for women with unmet needs for effective contraception. Younger women were more likely to report fertility, which raises questions about access to contraception. Women using ART for less than 5 years were more likely to have live births compared with women who were using ART for 10 years or more. The profile of HIV-positive women demands that integrated HIV care and reproductive health services should be available to support the reproductive rights of HIV-positive women and their partners to safely achieve their family planning goals while minimising the risk of both vertical and horizontal transmission of HIV.

\section{Twitter Tesfaye Regassa Feyissa @regassatesfaye}

Acknowledgements We thank the study participants and data collectors without whom the study would not have been possible. We would also like to thank Natalia Soeters for proof-reading this manuscript. Wollega University facilitated the data collection process.

Contributors Conception and design of the study: TRF, MH and DL. Conduct of the study: TRF, MH and DL. Analysis and interpretation of data: TRF, MH, PMF and DL. Drafting the manuscript and revising it critically: TRF, MH, PMF and DL. All authors have given final approval for the manuscript to be published.

Funding This study was funded by the Hunter Medical Research Institute/Greaves Family Postgraduate Top-Up Scholarship (grant number G1701582). The funders had no role in the study design, data collection and analysis, decision to publish or preparation of the manuscript. TRF is supported by The University of Newcastle International Postgraduate Research Scholarship (UNIPRS) and The University of Newcastle Research Scholarship Central 50:50 (UNRSC 50:50) and a Greaves Family Postgraduate Top-Up Scholarship administered through the Hunter Medical Research Institute. MLH is supported by an Australian Research Council Discovery Early Career Researcher Award (DECRA).

Competing interests None declared.

Patient consent for publication Not required.

Ethics approval Ethical approval was obtained from the Human Research Ethics Committee of The University of Newcastle, Australia (H-2017-0289) and the Oromia Regional State Health Bureau Research Ethics Committee, Ethiopia (BEFO/ HBISH/1-16/257).

Provenance and peer review Not commissioned; externally peer reviewed.

Data availability statement Due to the presence of potentially sensitive information, data are available upon request. This requirement was imposed by both ethics committees which approved the research protocol. Data request may be submitted to the Research Centre for Generational Health and Ageing, The University of Newcastle, Australia at rcgha@newcastle.edu.au.

Open access This is an open access article distributed in accordance with the Creative Commons Attribution Non Commercial (CC BY-NC 4.0) license, which permits others to distribute, remix, adapt, build upon this work non-commercially, and license their derivative works on different terms, provided the original work is properly cited, appropriate credit is given, any changes made indicated, and the use is non-commercial. See: http://creativecommons.org/licenses/by-nc/4.0/.

\section{ORCID iDs}

Tesfaye Regassa Feyissa http://orcid.org/0000-0002-6883-7312

Melissa L. Harris http://orcid.org/0000-0002-5733-9684

\section{REFERENCES}

1 Bongaarts J. A framework for analyzing the proximate determinants of fertility. Popul Dev Rev 1978;4:105-32.

2 Ethiopian Demographic and Health Survey. Demographic and health survey 2016; key indicators report. Addis Ababa: CSA, 2016.

3 Heffron R, Thomson K, Celum C, et al. Fertility intentions, pregnancy, and use of PreP and art for safer conception among East African HIV serodiscordant couples. AIDS Behav 2018;22:1758-65.

$4 \mathrm{Chi} \mathrm{BH}$, Adler MR, Bolu O, et al. Progress, challenges, and new opportunities for the prevention of mother-to-child transmission of HIV under the US president's emergency plan for AIDS relief. $J$ Acquir Immune Defic Syndr 2012;60 Suppl 3:S78-87.

5 Cooper D, Mantell JE, Moodley J, et al. The HIV epidemic and sexual and reproductive health policy integration: views of South African policymakers. BMC Public Health 2015;15:217.

6 Pellowski JA, Price DM, Harrison AD, et al. A systematic review and meta-analysis of antiretroviral therapy (art) adherence interventions for women living with HIV. AIDS Behav 2019;23:1998-2013.

7 Mirkuzie AH. Implementation and outcomes of guideline revisions for the prevention of mother-to-child HIV transmission in mother support programme, Addis Ababa, Ethiopia. PLoS One 2018;13:e0198438.

8 Federal Ministry of Health. The National strategic plan for elimination of mother to child transmission of HIV (e-MTCT of HIV) 2013-2015. Federal Ministry of Health Addis Ababa, 2013.

9 Karnon J, Orji N. Option B+ for the prevention of mother-to-child transmission of HIV infection in developing countries: a review of published cost-effectiveness analyses. Health Policy Plan 2016;31:1133-41.

10 Federal Ministry of Health. Accelerated plan for scaling up prevention of mother-to-child transmission services in Ethiopia Addis Ababa: FMOH, 2014. Available: http://pdf.usaid.gov/pdf_docs/PA00JWM5. pdf [Accessed Oct 2016].

11 World Health Organization. Global guidance on criteria and processes for validation: elimination of mother-to-child to transmission of HIV and syphilis, 2016. Available: http://apps.who. int/iris/bitstream/10665/112858/1/9789241505888_eng.pdf?ua=1\& ua $=1$ [Accessed Jan 2017].

12 Joint United Nations Programme on HIV/AIDS (UNAIDS). Ethiopian progress report UNAIDS, 2014

13 Yeatman S, Eaton JW, Beckles Z, et al. Impact of art on the fertility of HIV-positive women in sub-Saharan Africa. Trop Med Int Health 2016;21:1071-85.

14 Bongaarts $\mathrm{J}$. Modeling the fertility impact of the proximate determinants: time for a tune-up. Demogr Res 2015;33:535-60. 
15 Alene GD, Worku A. Differentials of fertility in North and South Gondar zones, Northwest Ethiopia: a comparative cross-sectional study. BMC Public Health 2008;8:397.

16 Chen W-J, Walker N. Fertility of HIV-infected women: insights from demographic and health surveys. Sex Transm Infect 2010;86 Suppl 2:ii22-7.

17 Marston M, Nakiyingi-Miiro J, Kusemererwa S, et al. The effects of HIV on fertility by infection duration: evidence from African population cohorts before antiretroviral treatment availability. AIDS 2017;31 Suppl 1:S69-76.

18 Marston M, Zaba B, Eaton JW. The relationship between HIV and fertility in the era of antiretroviral therapy in sub-Saharan Africa: evidence from 49 demographic and health surveys. Trop Med Int Health 2017;22:1542-50.

19 Marston M, Zaba B, Eaton JW. Relative patterns of sexual activity and fertility among HIV positive and negative women-Evidence from 46 DHS. PLoS One 2018;13:e0204584.

20 Marston M, Nakiyingi-Miiro J, Hosegood V, et al. Measuring the impact of antiretroviral therapy roll-out on population level fertility in three African countries. PLoS One 2016;11:e0151877.

21 Alibhai A, Martin LJ, Kipp W, et al. Quality of life of HIV patients in a rural area of Western Uganda: impact of a community-based antiretroviral treatment program. Curr HIV Res 2010;8:370-8.

22 Pearson CR, Cassels S, Kurth AE, et al. Change in sexual activity 12 months after art initiation among HIV-positive Mozambicans. AIDS Behav 2011;15:778-87.

23 Kabami J, Turyakira E, Biraro S, et al. Increasing incidence of pregnancy among women receiving HIV care and treatment at a large urban facility in Western Uganda. Reprod Health 2014;11:81.

24 Myer L, Carter RJ, Katyal M, et al. Impact of antiretroviral therapy on incidence of pregnancy among HIV-infected women in sub-Saharan Africa: a cohort study. PLoS Med 2010;7:e1000229.

25 Wessman M, Aho I, Thorsteinsson K, et al. Perception of sexuality and fertility in women living with HIV: a questionnaire study from two Nordic countries. J Int AIDS Soc 2015;18:19962.

26 Moore RD, Keruly JC. Cd4+ cell count 6 years after commencement of highly active antiretroviral therapy in persons with sustained virologic suppression. Clin Infect Dis 2007;44:441-6.

27 Palella FJ, Armon C, Chmiel JS, et al. CD4 cell count at initiation of ART, long-term likelihood of achieving CD4 $>750 \mathrm{cells} / \mathrm{mm} 3$ and mortality risk. J Antimicrob Chemother 2016;71:2654-62.

28 Central Statistical Agency (CSA) [Ethiopia]. Population projection of Ethiopia for all regions at Wereda level from 2014 - 2017. Addis Ababa: Central Statistical Agency, 2013.

29 von Elm E, Altman DG, Egger M, et al. The strengthening the reporting of observational studies in epidemiology (STROBE) statement: guidelines for reporting observational studies. Ann Intern Med 2007:147:573-7.

30 World Health Organization. Guideline on when to start antiretroviral therapy and on pre-exposure prophylaxis for HIV. Geneve: WHO, 2015.

31 Pagano M, Gauvreau K, Pagano M. Principles of biostatistics: Duxbury Pacific Grove, Ca, 2000.

32 Central Statistical Agency (CSA) [Ethiopia], ICF. Ethiopian demographic and health survey. Addis Ababa, Ethiopia: CSA, 2011: 82-108.

33 Choi Y, Li Q, Zachary B. Measuring fertility through mobile-phone based household surveys: methods, data quality, and lessons learned from PMA2020 surveys. Demogr Res 2018;38:1663-98.

34 Central Statistical Agency (CSA) [Ethiopia], ICF. Ethiopia demographic and health survey 2016. Addis Ababa, Ethiopia, and Rockville, Maryland, USA, 2016

35 Harris PA, Taylor R, Thielke R, et al. Research electronic data capture (REDCap)--a metadata-driven methodology and workflow process for providing translational research informatics support. J Biomed Inform 2009;42:377-81.

36 Munyazesa E, Emile I, Mutimura E, et al. Assessment of haematological parameters in HIV-infected and uninfected Rwandan women: a cross-sectional study. BMJ Open 2012;2:e001600

37 Gemmill A, Bradley SEK, van der Poel S. Reduced fecundity in HIVpositive women. Hum Reprod 2018;33:1158-66.

38 Nattabi B, Li J, Thompson SC, et al. A systematic review of factors influencing fertility desires and intentions among people living with HIV/AIDS: implications for policy and service delivery. AIDS Behav 2009;13:949-68.

39 Pinsky AN, Steenbergh K, Boyd HM, et al. Healthcare provider attitudes regarding the provision of assisted reproductive services for
HIV-affected couples in Addis Ababa, Ethiopia. Int J Gynaecol Obstet 2018;141:45-51.

40 Padian NS, McCoy SI, Karim SSA, et al. Hiv prevention transformed: the new prevention research agenda. Lancet 2011;378:269-78.

41 Melaku YA, Zeleke EG. Contraceptive utilization and associated factors among HIV positive women on chronic follow up care in Tigray region, Northern Ethiopia: a cross sectional study. PLoS One 2014;9:e94682.

42 Boerma JT, Weir SS. Integrating demographic and epidemiological approaches to research on HIV/AIDS: the proximate-determinants framework. J Infect Dis 2005;191 Suppl 1:S61-7.

43 Brubaker SG, Bukusi EA, Odoyo J, et al. Pregnancy and HIV transmission among HIV-discordant couples in a clinical trial in Kisumu, Kenya. HIV Med 2011;12:316-21.

44 Jhangri GS, Heys J, Alibhai A, et al. Unmet need for effective family planning in HIV-infected individuals: results from a survey in rural Uganda. J Fam Plann Reprod Health Care 2012;38:23-9.

45 Wolrd Health Organization. Hiv transmission through breastfeeding; a review of available evidence, 2007.

46 UNAIDS. Miles to go: global AIDS update 2017, 2018.

$47 \mathrm{MOH}$. Guidelines for prevention of mother-to-child transmission of HIV in Ethiopia. Addis Ababa: Federal HIV/AIDS Prevention and Control Office, 2011: 3-8.

48 Makumbi FE, Nakigozi G, Reynolds SJ, et al. Associations between HIV antiretroviral therapy and the prevalence and incidence of pregnancy in Rakai, Uganda. AIDS Res Treat 2011;2011:519492

49 Kaida A, Matthews LT, Kanters S, et al. Incidence and predictors of pregnancy among a cohort of HIV-positive women initiating antiretroviral therapy in Mbarara, Uganda. PLoS One 2013;8:e63411.

50 lyer JR, Van Rie A, Haberlen SA, et al. Subfertility among HIVaffected couples in a safer conception cohort in South Africa. Am J Obstet Gynecol 2019;221:48.e1-48.e18.

51 Ramjee G, Daniels B. Women and HIV in sub-Saharan Africa. AIDS Res Ther 2013:10:30.

52 Central Statistical Agency (CSA) [Ethiopia], ICF. Demographic and health survey: HIV prevalence report 2016. Addis Ababa, Ethiopia, and Rockville, Maryland, USA: CSA and ICF, 2016.

53 Matthews LT, Mukherjee JS. Strategies for harm reduction among HIV-affected couples who want to conceive. AIDS Behav 2009;13 Suppl 1:5-11.

54 Matthews LT, Beyeza-Kashesya J, Cooke I, et al. Consensus statement: supporting safer conception and pregnancy for men and women living with and affected by HIV. AIDS Behav 2018;22:1713-24.

55 Feyissa TR, Harris ML, Loxton D. Discussing reproductive plans with healthcare providers by sexually active women living with HIV in Western Ethiopia. AIDS Behav 2020. doi:10.1007/s10461-02002833-1. [Epub ahead of print: 24 Mar 2020].

56 EPHA. Ethiopian Public Health Association: Identifying HIVIAIDS, Sexually transmitted Infection and Tuberculosis Research Gaps and Priority Setting Agenda in Ethiopia, 2004. Available: <http://etpha. org/publications/other-publications.html?download=398> [Accessed Nov 2014].

57 Patel P, Borkowf CB, Brooks JT, et al. Estimating per-act HIV transmission risk: a systematic review. AIDS 2014;28:1509-19.

58 Reynolds SJ, Makumbi F, Nakigozi G, et al. Hiv-1 transmission among HIV-1 discordant couples before and after the introduction of antiretroviral therapy. AIDS 2011;25:473-7.

59 Matthews LT, Milford C, Kaida A, et al. Lost opportunities to reduce periconception HIV transmission: safer conception counseling by South African providers addresses perinatal but not sexual HIV transmission. J Acquir Immune Defic Syndr 2014;67 Suppl 4:S210-7.

60 Elul B, Wools-Kaloustian KK, Wu Y, et al. Untangling the relationship between antiretroviral therapy use and incident pregnancy: a marginal structural model analysis using data from 47,313 HIVpositive women in East Africa. J Acquir Immune Defic Syndr 2016:72:324

61 Westreich D, Evans D, Firnhaber C, et al. Prevalent pregnancy, biological sex, and virologic response to antiretroviral therapy. $J$ Acquir Immune Defic Syndr 2012;60:489-94.

62 Nguyen RHN, Gange SJ, Wabwire-Mangen F, et al. Reduced fertility among HIV-infected women associated with viral load in Rakai district, Uganda. Int J STD AIDS 2006;17:842-6.

63 Sisay MM, Yirgu R, Gobezayehu AG, et al. A qualitative study of attitudes and values surrounding stillbirth and neonatal mortality among grandmothers, mothers, and unmarried girls in rural Amhara and Oromiya regions, Ethiopia: unheard souls in the backyard. $J$ Midwifery Womens Health 2014;59 Suppl 1:S110-7. 